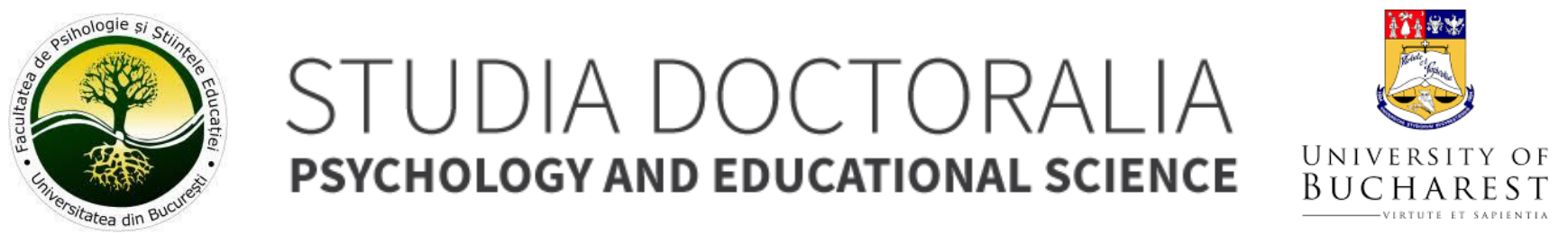

\title{
The Relationship between Burnout and Counterproductive Work Behavior. The Role of Compassion Fatigue and Organizational Justice
}

Ana-Maria Mărgulescu

University of Bucharest

\section{ARTICLE INFO}

Article history:

Received 11-July-2020

Accepted 31-August-2020

Available online 01-November-2020

This article should be cited as: Mărgulescu, A-M. (2020). The Relationship between Burnout and Counterproductive Work Behavior. The Role of Compassion Fatigue and Organizational Justice. Studia Doctoralia. Psychology and Educational Science, 11(2), 72-80. https://doi.org/10.47040/sd/sdpsych.v11i2.113

This is an open access article under the CC BY license (http://creativecommons.org/licenses/by/4.0/).

University of Bucharest, Department of Psychology, 90 Panduri Av, Bucharest, RO.

Tel.: +40 (0) 31-425.34.45

E-mail address: anamariamargulescu@gmail.com

\section{ABSTRACT}

Counterproductive behavior is a phenomenon that affects both organizations and employees. This research aimed, in an exploratory manner, to observe the relationship between counterproductive behaviors, burnout, compassion fatigue, and organizational justice at the workplace. For this study, data were collected from 100 employees through a Google Forms questionnaire. From the statistical analysis, CF does not represent a mediator of the relationship between burnout and counterproductive behaviors, nor is organizational justice a moderator of the relationship between burnout and counterproductive behaviors. The statistical analysis was performed in the JAMOVI 1.2.12 program. .

Keywords: burnout, counterproductive work behavior, compassion fatigue, organizational justice, mediated moderation

\section{INTRODUCTION}

\section{The importance of the criterion (CWB)}

Counterproductive work behaviors (CWB) are intentional behaviors produced by employees to have a negative impact on the organization and its members (Spector \& Fox, 2005). These types of behaviors were conceptualized according to certain criteria, such as the negative (Yao, Fan, Guo, \& Lee, 2014) and violent behavior of the employee (Lian et al., 2014) on the company or on his colleagues. Unfortunately, counterproductive work behaviors are dangerous for the workplace and directly affects its functioning as an environment and harms on employee effectivenes.

Several studies (e.g., Ogińska-Bulik, 2005) have reached a common conclusion related to counterproductive 
behaviors. They are produced by people who are unable to control their emotions, establish relationships with colleagues, employees, customers and, subsequently, these things lead to burnout.

\section{The relationship with the predictor (Burnout)}

Burnout is a three-dimensional concept: emotional exhaustion, depersonalization and personal accomplishment (Lee, Yen, Fetzer, \& Chien, 2015; Maslach, 2003). Emotional exhaustion is the core concept of burnout and it occurs when an individual is emotionally overworked. Depersonalization occurs when the person takes on certain behaviors that are not appropriate for him and he develops afterwards a careless attitude towards his duties due to pressure from the place for work. The last dimension, personal accomplishment refers to the feeling of low accomplishment in terms of workload, which indicates a change in perception. Putting it differently, burnout is a complex construct that reflects the emotional and physical reaction in the presence of repetitive stress, which changes the perception and detaches mentally from yourself (Schaufeli \& Salanova, 2014).

The best model known is from Spector and Fox (2005), the Stressor-Emotion Model which is usually used in organizational environment to explain the elements that lead to counterproductive behavior. The model argues that the working environment and conditions can contribute to counterproductive behaviors. Starting from this idea, it can be seen that these behaviors are the response to the stress to which the employee is under (Spector \& Fox, 2005).

In order to support the previous claim, the Job DemandResources (JD-R) Model (Demerouti, Bakker, Nachreiner, \& Schaufeli, 2001) is also used to explain how an employee gets burnout and can adhere to counterproductive behaviors. The JD-R model postulates that the job responsibilities can be grouped in two general categories, namely job demands and job resources (Bakker, Demerouti, \& Verbeke, 2005).

\section{Burnout and Counterproductive Work Behavior}

Burnout can occur among people who work in the medical field or in an area that involves providing constant support. The medical workforce, especially nurses, is most likely to develop burnout. According to Nantsupawat (Kunaviktikul, Nantsupawat, Wichaikhum, Thienthong, \& Poghosyan, 2017), the nurses usually suffers from burnout due to the physical and emotional demands of the place of work. It has been found that high levels of work can increase burnout exposure faster (Laschinger, Finegan, \& Wilk, 2011), while burnout is positively associated with counterproductive work behaviors (Bans, Whelpley, Oh, \& Shin, 2012; Bolton, Harvey, Grawitch, \& Barber, 2012). In a similar study in which the relationship between emotional exhaustion and counterproductive work behaviors, Krischer, Penney, and Hunter (2010) found that employees who reported being emotionally exhausted were more likely to display counterproductive work behavior. At the same time, Liang and Hsieh (2007) found that only depersonalization, of all dimensions of the burnout construct, predicts significantly counterproductive work behaviors, which was demonstrated on a sample of 303 flight attendants from Taiwan.

Uchenna (2013) conducted a study on perceived organizational support about work burnout and counterproductive work behaviors on a sample of 328 employees who had very demanding emotional jobs, in Nigeria. The results showed that employees who reported feeling burnout also had increased their likelihood of involvement in counterproductive work behaviors despite those who did not report burnout at work.

\section{Mediator}

Compassion fatigue (CF), known as secondary shock and secondary reaction to stress, describes a certain type of stress that results from helping or the desire to help those who are traumatized or who have a constrained emotional behavior. Although CF is sometimes called burnout, it is still a different concept. In contrast to burnout, $\mathrm{CF}$ is treatable and may be less predictable. The onset may be sudden, while burnout occurs over a much longer period of time. Moreover, in very serious cases of burnout can put the person in a position to change their job or field works, but in the case of $\mathrm{CF}$, treatment or prevention measures can be taken to avoid being subjected to activity changes (Figley, 2002).

The concept of CF was originally used by Joinson (1992) who referred to nurses' experiences with burnout. Figley (2001) developed this concept from a description of the Compassion Stress / Fatigue model Model (Figley, 1995). In most cases, the act of compassion, described as "bearer of the suffering of others" (Figley, 2002, p.1434), implies the relationship between concern with traumatized victims and $\mathrm{CF}$.

Craig and Sprang (2010) conducted a study that explores the impact of using evidence-based practices on $\mathrm{CF}$, burnout, and compassion satisfaction. Using workers from the National Association of Social Aids from 2003 and from the Association of Psychology from America (APA), 2,000 practitioners who self-identified as having a specialty in traumatology, questionnaires were sent to them for that study. Since 2000, 532 of those traumatologists have responded. Of that sample, $47 \%$ had a master's degree and $52 \%$ had a doctoral degrees. The sample was also composed of $34 \%$ men and $65 \%$ women aged $27-83$. Right of these data, $98 \%$ of participants indicated that they had patients who suffered from postraumatic stress disorder (PTSD) (Craig \& Sprang, 2010).

$\mathrm{H} 1$ : We assume that there is a significant positive relationship between burnout, compassion fatigue and counterproductive behaviors. 


\section{Moderator}

The perceptions to which an organization provides appropriate treatment, respect, promotional resources, and rewards to their employees are conceptualized under organizational justice (e.g., Ambrose \& Schiminke, 2009).

Perceptions of organizational justice are divided into three categories: perceptions of distributive justice; perceptions of procedural justice; respectively perceptions of interactional justice (e.g., Folger \& Cropanzano, 1998)

\section{Dimensions of organizational justice \\ Distributive justice}

Distributive justice is concerned that not everyone workers are treated the same; the allocation of results is differentiated at work for various reasons. People are worried about whether or not they have received their "only share" salary. Sometimes things are distributed correctly, for example, the most qualified person is promoted. Other times they are not, as when advancement is based on political relations with senior management (Cropanzano, Bowen, \& Gilliland, 2007).

\section{Procedural justice}

Procedural justice refers to how the results are allocated. Procedural justice establishes certain principles that specify and governs the roles of participants in decisionmaking processes.

\section{METHODOLOGY}

\section{Participants and procedure}

Data was collected using a Google Form during the 11th October-28th December, 2019, the form with the criterion of inclusion of persons who have a job at the time of completing the questionnaire. They had to answer to Maslach Inventory of Burnout Measurement of 16 items, Quality of professional life: subscale for CF of 20 items, Counterproductive Work Behavior Questionnaire of 10 items, for organizational justice the Sweeney Procedural Justice Measurement Scale and McFarlin of 13 items and Sweeney and McFarlin's Distributive Justice Measurement Scale of 11 items, plus 4 questions regarding dermographic data (age, gender, field of activity and seniority at work).

The sample consisted of 100 employees from public and private institutions, from various sectors of activity, such as retail (25.4\%), IT (13\%), economic $(9.4 \%), \mathrm{HR}(8.7 \%)$ and marketing (8\%). Respondents were both female $(90 \%)$ and male (10\%), aged between 18 and 53 years $(M=1.16, S D$ $=.36$ ). The number of participants was determined by power analysis performed by the program $G$ * Power version 3.1.9.2 (Faul, Erdfelder, Buchner, and Lang, 2009; Faul, Erdfelder, Lang, and Buchner, 2007).

\section{Instruments}

Burnout. It was measured using both quantitative and qualitative data. Maslach Burnout Measurement Inventory
Procedural justice is essential for maintaining institutional legitimacy. When there is a process of selecting personnel, individuals may receive certain results. According to Tyler and Blader (2000), favoring the outcomes tends to affect satisfaction and that particular decision. What is more interesting is that procedural justice affects what workers think about the organization as a whole. If the process is perceived as fair, employees show greater loyalty and more availability. There are also more unlikely to betray the institution or the leaders.

\section{Interactional Justice}

Interactional justice can be the simplest of those three components. It refers to the way one person treats another. One person interacts with another only if they share information appropriately and avoid rude or harsh comments and behaviors. In other words, there are two aspects of interactional justice (Colquitt, Conlon, Wesson, Porter \& Ng, 2001). The first part, sometimes called informational justice refers to the fact that one is truthful and provides adequate justifications when things are going wrong. The second part, called interpersonal justice, refers to respect and the dignity with which he treats another.

$\mathrm{H} 2$ : We assume that there is a significant positive relationship between burnout, justice, organizational and counterproductive behaviors.

(Schaufeli, Leiter, Maslach, \& Jackson, 1996) was translated into Romanian by Coralia Sulea and contains 16 items ("I doubt the significance of my work"), scored on 6 steps (0never and 6 daily), with a Cronbach Alpha index of .95 .

Compassion Fatigue. Quality of professional life: Satisfaction compassion and exhaustion (Stamm, 2009) was translated into this study and the CF subscale was used which consists of 20 items ("I feel overwhelmed because my workload seems endless "), with Cronbach Alpha index of 81 .

Counterprodutive Work Behaviors (Spector, Bauer, \& Fox, 2010) was translated into Romanian by Coralia Sulea and Dragoș lliescu and contains 10 items ("Attended to people from outside the organization terribly hard work ") It is measured on the Likert scale in five steps (1-never, 5- daily), the Cronbach Alpha index being .85 .

Organizational Justice. In order to measure organizational justice, it was used both a scale for measuring procedural organizational justice and a scale for distributive organizational justice. Procedural Justice Measurement Scale by Sweeney and McFarlin (Sweeney, \& McFarlin 1997) was translated by Andrei Georgescu and contains 13 items ("It is impossible to change things here"), measured on a scale Likert in five steps (1-strong disagreement, 5strong agreement), the Cronbach Alpha index being of 63 . Sweeney and McFarlin's Distributive Justice Measurement 
Scale (Sweeney, \& McFarlin, 1997) was translated by Andrei Georgescu. The scale includes 11 items ("In this system, financial rewards are rarely related to performance employee.) measured on the five-step Likert scale (1-strong disagreement, 5-strong agreement) the Cronbach Alpha index is 0.65 .

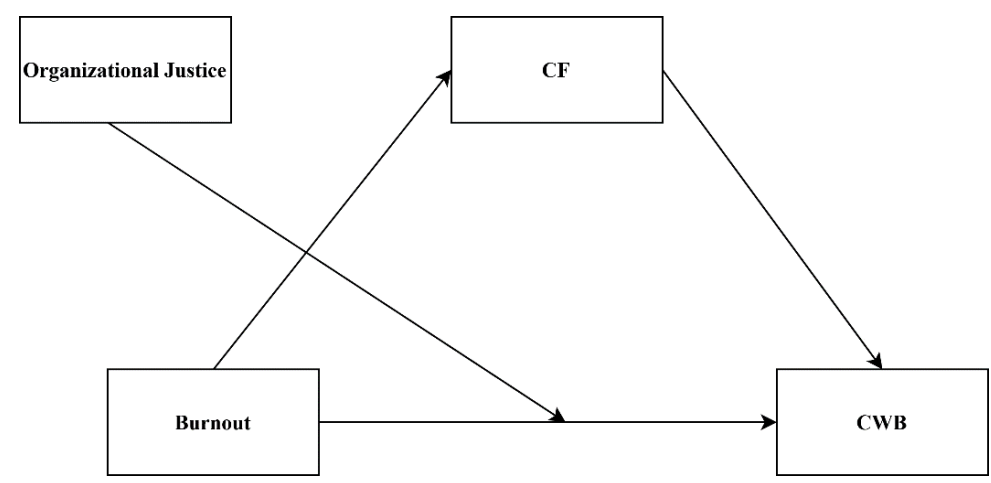

Figure 1. The mediated moderation model

\section{RESULTS}

Descriptive statistics. In descriptive statistics, set out in Table 1, the specific media and standard deviation were analyzed using quantitative variables regarding counterproductive work behaviors $(M=20 ; S D=6.06)$, burnout $(M=42.6 ; S D=17.9), C F(M=47 ; S D=11.3)$, procedural organizational justice $(M=41.1 ; S D=11.4)$ and distributive organizational justice $(M=33.7 ; S D=9.12$ ). Given variables regarding gender, fields of work and age, they being of qualitative type and categorically, they were coded, in turn, as follows: gender ( $1=$ Male; 2 = Female), field of activity ( $1=$ Retail; 2 = Economic; $3=\mathrm{IT} ; 4=\mathrm{MAI})$, age (1 = 18-30 years; 2 = 3060 years), burnout (BSUM), CF (CFSUM), counterproductive behaviors products (CWBSUM), distributive organizational justice and procedural justice (JORGSUM).

Table 1. Descriptive statistics

\begin{tabular}{lrcccc}
\hline \multicolumn{1}{l}{ BSUM } & CFSUM & CWBSUM & JODSUM & JOPSUM \\
\hline $\mathrm{N}$ & 100 & 100 & 100 & 100 & 100 \\
Missing & 0 & 0 & 0 & 0 & 0 \\
Mean & 42.6 & 47.0 & 20.0 & 33.7 & 41.1 \\
Median & 39.0 & 45.0 & 18.0 & 33.0 & 41.0 \\
Standard deviation & 17.9 & 11.3 & 6.06 & 9.12 & 11.4 \\
Minimum & 16.0 & 28.0 & 10.0 & 13.0 & 21.0 \\
Maximum & 86.0 & 76.0 & 41.0 & 52.0 & 65.0 \\
\hline
\end{tabular}


Analysis and interpretation of inferential statistics. The results obtained from the first statistical operation that had as object of study the mediating effect of compassion (CF) on the relationship between burnout and counterproductive behaviors, showed that, although the total and direct effect are significant $(p<.001)$, the indirect effect resulting from the data analysis is insignificant $(p<.11)$. Consequently, the mediating effect of $\mathrm{CF}$ in the relationship between burnout and counterproductive work behavior is statistically insignificant (Table 2).

Table 2. Mediation

\begin{tabular}{|c|c|c|c|c|}
\hline Effect & Estimate & $S E$ & $Z$ & $p$ \\
\hline Indirect & .03 & .02 & 1.56 & .12 \\
\hline Direct & .06 & .04 & 1.63 & .10 \\
\hline Total & .09 & .03 & 2.79 & .01 \\
\hline
\end{tabular}

Secondly, we present the results of the moderation that aimed to measure the moderating effect of organizational justice on the relationship between burnout and counterproductive behaviors. According to Table 2, the relationship between counterproductive behaviors and burnout is significant $(p<.001)$ and also the relationship between $\mathrm{CF}$ and counterproductive behaviors is significant. However, the moderation between organizational justice over the relationship between burnout and counterproductive behaviors came out statistically insignificant (Table 3).

Table 3. Moderation

Estimate

SE

Z $\quad p$

BSUM

.05

.03

1.57

.12

JORGSUM

$-.08$

.03

$-2.83$

.01

BSUM * JORGSUM

.01

.01

1.52

Table 4. Correlation Matrix

\begin{tabular}{|c|c|c|c|c|}
\hline & BSUM & CFSUM & CWBSUM & JORGSUM \\
\hline BSUM & - & - & & \\
\hline CFSUM & $.50^{* *}$ & - & & \\
\hline CWBSUM & $.27^{\star *}$ & $.27^{\star *}$ & & \\
\hline JORGSUM & $-.53^{* *}$ & $-.26^{* *}$ & $-.36^{* *}$ & - \\
\hline
\end{tabular}


Table 5. Effect size between burnout and organizational justice

\begin{tabular}{lll}
\hline Model & $\mathrm{R}$ & $R^{2}$ \\
\hline 1 & .53 & .27
\end{tabular}

A determination coefficient of .27 can be observed, which expresses the fact that $27 \%$ of the burnout is expressed by the organizational justice. Given the relatively low correlation coefficient, it is important to note that the relationship between the two constructs is, in fact, weak and suggests that the way the employee is treated is not an important factor in the context of the relationship between burnout and counterproductive work behaviors in which the employee suffering from burnout is supposed to be less likely to focus on how he is being treated, given his psychological state.

Table 6. Effect size between counterproductive behavior and burnout

\begin{tabular}{lll}
\hline Model & $\mathrm{R}$ & $R^{2}$ \\
\hline 1 & .27 & .07
\end{tabular}

A determination coefficient of .07 can be observed, which expresses the fact that $7 \%$ of the counterproductive work behaviors are expressed by burnout. Given the relatively low coefficient, the relationship is poor, suggesting that most people who suffer from burnout will not be able to turn to counterproductive work behaviors in the workplace because it is assumed that they are less likely to focus on the external environment. and more on one's own psychological state.

\section{DISCUSSION}

In the present study, following the data analysis, CF is not a mediator of the relationship between burnout and counterproductive work behaviors, therefore not all people are characterized by specific attributes of CF, but it cannot be argued with certainty that they will turn to counterproductive work behaviors.

Another point of view is that there is a direct relationship between $\mathrm{CF}$ and burnout, which means that respondents characterized by burnout can also suffer from $C F$. Additionally, the indirect relationship between CF and counterproductive behaviors can be observed, which means that those who suffer from CF, but not necessarily from burnout, cannot end up expressing counterproductive work behaviors.
Table 7. Effect size between counterproductive behavior and organizational justice

\begin{tabular}{lll}
\hline Model & $\mathrm{R}$ & $R^{2}$ \\
\hline 1 & .36 & .13 \\
\hline
\end{tabular}

A coefficient of determination of .13 can be observed, which expresses the fact that $13 \%$ of organizational justice is expressed through counterproductive work behaviors. Being a weak relationship, we deduced that people who perceive non-compliance with organizational justice at work either prefer to ignore this fact or show indifference to the way they are treated by the employer.

Table 8. Effect size between compassion fatigue and organizational justice

\begin{tabular}{lll}
\hline Model & $\mathrm{R}$ & $R^{2}$ \\
\hline 1 & .26 & .06 \\
\hline
\end{tabular}

A determination coefficient of .06 can be observed, which expresses the fact that $6 \%$ of the CF is expressed through organizational justice, thus resulting in a weak relationship. In the current context, at work, if people suffer from CF they tend to show feelings of indifference or ignorance about how they are treated by the employer, due to the saturation they have reached.

Moreover, the results support the hypothesis that those suffering from $\mathrm{CF}$ are usually people working in the health field, compared to other specified fields. and analyzed in this paper, or those who have a very high workload, which could lead to decreased tolerance and loss of compassion for suffering people, although this necessarily means that they will behave abusively towards the patient or workplace.

In the current paper, Secondary Traumatic Stress (STS) was operationalized in this paper as post-traumatic stress because, together with $\mathrm{CF}$, these are the psychological states that the employee may reach due to risk factors, such as long working hours (Boscarino, Figley, \& Adams, 2004).

In the study published by Ginny and colleagues (2007), organizational factors, such as workplace environments and employee supervision, were observed to mitigate the effects of STS and burnout (Boscarino et al., 2004; Korkeila, 
Kumpulainen, Toivola, Rasanen, \& Kalimo, 2003; Ortlepp \& Friedman, 2002; Webster \& Hackett, 1999). Autonomy and control appear to be mitigating factors only for burnout (AbuBader, 2000; Vredenburgh, Carlozzi, \& Stein, 1999), while access to own coping resources has attenuated both burnout and STS (Abu-Bader , 2000; Ortlepp \& Friedman, 2001).

This paper is a first attempt to measure the relationship between $\mathrm{CF}$, burnout, counterproductive work behaviors and organizational justice on a sample from Romania. So far, CF has been explained only on the medical model, related to how nurses feel (i.e., from oncology departments) when taking care for people with terminal illnesses (Wentzel \& Brysiewocz, 2018) or people working in the field of health public (Smart et al., 2013). In these studies, the whole ProQOL scale was applied, which also measures the quality of life, but in the current study only the CF subscale was used. Also, these studies showed a positive relationship between burnout and CF, which can be seen in the current study.

In this sense, it is likely that the reason why CF does not mediate the relationship between burnout and counterproductive work behaviors is that there is a possibility that people may not focus on offering their help and time to the detriment of others. This could be caused by the state of exhaustion in which the employee is, but also by the feelings of helplessness he experiences.

In the case of the moderation relationship, the fact that organizational justice moderates the relationship between burnout and counterproductive behaviors, it turned out to be insignificant. In the current study, scales for organizational justice were used together (i.e., distributive justice, procedural justice) which may have influenced the relationship. Brotheridge's (2003) study found that perception of procedural justice is an important predictor of emotional exhaustion, while distributive justice was a secondary predictor (Moliner, Martinez-Tur, Peiro, Ramos, \& Cropanzano, 2005).

According to the analyzes performed in this study, it can be seen that people who have personality traits predisposing to burnout, but not to counterproductive work behaviors, will not be affected by the attitude of bosses towards them. There is a chance that these people will be loyal regardless of the company's situation and behavior towards them, a fact supported by the respondents' data.

The participants in this study came from 3 major areas, namely Retail, IT and Economic, areas that allow an emotional distance from customers. It should not be overlooked, however, that CF does not predict counterproductive behaviors, so there is a high chance that people suffering from burnout and not CF will engage in counterproductive behaviors, either against their own bosses, colleagues or the company..

\section{Limitations and further research}

The study was conducted over a short period of time and the time element is a key element in the paper, it is limited to a few months. Also, the sample consisted of all branches of the labor market and did not have a specific target (i.e., target population) for a certain category. One can also take into account the error of understanding the items by the respondents or the random answers or offered with disinterest.

The CF construct is still unknown and little studied in the organizational field in Romania and there is a possibility that the items of the scale are not fully understood. Moreover, most respondents had difficulty understanding why $\mathrm{CF}$ is a different construct than burnout. At the scale for counterproductive behaviors, there may be answers that are not entirely true, as they are desirable. This argument can be explained by the fact that people tend, most of the time, to fabricate answers because the real ones actually hide a negative or aggressive behavior towards someone or the organization they belong to (Shkoler, \& Tziner, 2017).

Another factor that should be taken into account is that the questions in the data collection questionnaire were completed on an online platform, without the presence of the researcher, which may lead to random answers. Respondents may also not have been sufficiently focused and honest by the end of the questionnaire.

The model presented in this study deserves more attention in the future. The measurement was taken once, giving the model having a predominantly exploratory, not necessarily confirmatory, character. Therefore, repeated measurements can be made over a longer period of time to see how people relate to work experience. I believe that emphasis should be placed on areas other than medicine in order to be able to extend the boundaries made by the literature on this model.

Future studies could take into account a more representative sample, with a much more rigorous delimitation of participants than in the current study and a much larger number of participants. 


\section{REFERENCES}

Abu-Bader, S. H. (2000). Work satisfaction, burnout, and turnover among social workers in Israel: A causal diagram. International Journal of Social Welfare, 9, 191-200 DOI:10.1111/1468-2397.00128.

Ambrose, M. L., \& Schminke, M. (2009). The role of overall justice judgments in organizational justice research: a test of mediation. Journal of Applied Psychology, 94, 491-500. DOI: 10.1037/a0013203.

Bakker, A. B., Demerouti, E., \& Euwema, M. C. (2005). Job resources buffer the impact of job demands on burnout. Journal of Occupational Health Psychology, 10(2), 170 180. DOI: 10.1037/1076-8998.10.2.170.

Bans, G. C., Whelpley, C. E., Oh, I., \& Shin, K. (2012). How are emotionally exhausted employees harmful? International Journal of Stress Management, 19(3), 198216. DOI: $10.1177 / 0021886317749163$.

Brotheridge, C. M. (2003). The role of fairness in mediating the effects of voice and justification on stress and other outcomes in a climate of organizational change. International Journal of Stress Management, 10, 253-268. DOI:10.1037/1072-5245.10.3.253.

Bolton, L. R., Harvey, R. D., Grawitch, M. J., \& Barber, L. K. (2012). Counterproductive work behaviours in response to emotional exhaustion: A moderated meditational approach. Stress \& Health, 28(3), 222-233. DOI: 10.1002/smi.1425.

Boscarino, J. A., Figley, C. R., Adams, R. E. (2004). Compassion fatigue following the September 11 terrorist attacks: A study of secondary trauma among New York social workers. International Journal of Emergency Mental Health, 6, 110.

Craig, C. D., \& Sprang, G. (2010). Compassion satisfaction, compassion fatigue, and burnout in a national sample of trauma treatment therapists. Anxiety, Stress, \& Coping, 23, 319-339. DOI: 10.1080/10615800903085818.

Cropanzano, R., Bowen, D. E., \& Gilliland, S. W. (2007). The Management of Organizational Justice. Academy of Management Perspectives, 21(4), 34-48. DOI:10.5465/amp.2007.27895338.

Colquitt, J. A., Conlon, D. E., Wesson, M. J., Porter, C. O. L. H., \& Ng, K. Y. (2001). Justice at the millennium: A metaanalytic review of 25 years of organizational justice research. Journal of Applied Psychology, 86, 425-445. DOI: 10.1037/0021-9010.86.3.425.

Demerouti, E., Bakker, A. B., Nachreiner, F., \& Schaufeli, W. B. (2001). The job demands resources model of burnout. Journal of Applied Psychology, 86(3), 499-512.DOI: 10.1037//0021-9010.86.3.499.

Faul, F., Erdfelder, E., Buchner, A., \& Lang, A.-G. (2009). Statistical power analyses using $G^{*}$ Power 3.1: Tests for correlation and regression analyses. Behavior Research Methods, 41, 1149-1160. DOI: 10.3758/BRM.41.4.1149.

Faul, F., Erdfelder, E., Lang, A.-G., \& Buchner, A. (2007). G*Power 3: A flexible statistical power analysis program for the social, behavioral, and biomedical sciences. Behavior Research Methods, 39, 175-191. DOI: 10.3758/BF03193146.

Figley, C. R. (2001). Compassion fatigue as secondary traumatic stress: An overview. In C. R. Figley (Ed.), Compassion fatigue: Coping with secondary traumatic stress disorder (2nd ed., pp. 1-20). New York, NY: Bruner/Mazel.

Figley, C. R. (2002). Compassion fatigue: Psychotherapists' chronic lack of self care. Journal of Clinical Psychology, 58, 1433-1441. DOI: 10.1002/jclp.10090.

Figley C. (1995). Compassion Fatigue: Coping with Secondary Stress Disorder in Those Who Treat the Traumatised. Brunner/Mazel; Bristol, UK: 1995.

Folger, R. G., \& Cropanzano, R. (1998). Organizational justice and human resource management (7). Thousand Oaks, CA: Sage Publications.

Joinson, C. (1992). Coping with compassion fatigue. Nursing, 22, 116-122. DOI:10.1097/00152193-19920400000035.

Hudnall Stamm, B. (2009). The ProQOL manual. Retrieved November, 26, 2019. Retrieved from www. proqol.org.

Krischer, M. M., Penney, L. M., \& Hunter, E. M. (2010). Can counterproductive work behaviors be productive? CWB as emotion-focused coping. Journal of Occupational Health Psychology, 15(2), 154-166. DOI: 10.1037/a0018349.

Korkeila, J. A., Toyry, S., Kumpulainen, K., Toivola, J. M., Rasanen, K., \& Kalimo, R. (2003). Burnout and selfperceived health among finnish psychiatrists and child psychiatrists: A national survey. Scandinavian Journal of Public Health, 31, 85-91. DOI: 10.1080/14034940210133880.

Laschinger, H. K. S., Finegan, J., \& Wilk, P. (2011). Situational and dispositional influences on nurses' workplace well-being: The role of empowering unit leadership. Nursing Research, 60(2), 124-131. DOl: 10.1097/NNR.0b013e318209782e.

Liang, S.-C., \& Hsieh, A.-T. (2007). Burnout and workplace deviance among flight attendants in Taiwan. Psychological Report, 101(2), 457-468. DOI: 10.2466/pr0.101.2.457-468. Lian, H., Brown, D. J., Ferris, D. L., Liang, L. H., Keeping, L. M., \& Morrison, R. (2014). Abusive supervision and Retaliation: A self-control framework. Academy of Management Journal, 57(1), 116-139. DOI: 10.5465/amj.2011.0977. 
Lee, H. F., Yen, M., Fetzer, S., \& Chien, T. W. (2015). Predictors of burnout among nurses in Taiwan. Community Mental Health Journal, 51(6), 733-737. DOI: 10.1007/s10597-014-9818-4.

Maslach, C. (2003). Job Burnout. Current Directions in Psychological Science, 12(5), 189-192. DOI:10.1111/14678721.01258.

Moliner, C., Martínez-Tur, V., Peiró, J. M., Ramos, J., \& Cropanzano, R. (2005). Relationships between organizational justice and burnout at the work-unit level. International Journal of Stress Management, 12, 99-116.

Nantsupawat, A., Kunaviktikul, W., Nantsupawat, R., Wichaikhum, O.-A., Thienthong, H., \& Poghosyan, L. (2017). Effects of nurse work environment on job dissatisfaction, burnout, and intention to leave. International Nursing Review, 64(1), 91-98. DOI:10.1111/inr.12342.

Ogińska-Bulik, N. (2005). Emotional intelligence in the workplace: Exploring its effects on occupational stress and health outcomes in human service workers. International Journal of Occupational Medicine and Environmental Health, 18(2), 167-175. DOI:10.3390/safety5020030.

Ortlepp, K. \& Friedman, M. (2002). Prevalence and correlates of secondary traumatic stress in workplace lay trauma counselors. Journal of Traumatic Stress, 15, 213222. DOI: $10.1023 / A: 1015203327767$.

Ortlepp, K. \& Friedman, M. (2001). The relationship between sense of coherence and indicators of secondary traumatic stress in non-professional trauma counselors. South African Journal of Psychology, 31, 38-46. DOl: 10.1177/008124630103100205.

Schaufeli, W. B., \& Salanova, M. (2014). Burnout, boredom and engagement in the workplace. In M. C. W. Peeters, J. de Jonge, \& T. W. Taris (Eds.). An introduction to contemporary work psychology (pp. 293-320). (1st ed.). Hoboken: John Wiley \& Sons.

Schaufeli, W. B., Leiter, M. P., Maslach, C., \& Jackson, S. E. (1996). Maslach Burnout Inventory-General Survey. In C. Maslach, S. E. Jackson, M. P. Leiter (Eds.), The Maslach Burnout Inventory: Test manual (3rd ed., pp. 22-26). Palo Alto, CA: Consulting Psychologists Press. Retrieved from http://researchcentral.ro/index.php?action=listateste\&ID=41 2.

Shkoler, O., \& Tziner, A. (2017). The mediating and moderating role of burnout and emotional intelligence in the relationship between organizational justice and work misbehavior. Revista de Psicología Del Trabajo y de Las Organizaciones, 33(2), 157-164. DOI:10.1016/j.rpto. 2017.05.002.

Smart, D., English, A., James, J., Wilson, M., Daratha, K. B., Childers, B., \& Magera, C. (2013). Compassion fatigue and satisfaction: A cross-sectional survey among US healthcare workers. Nursing \& Health Sciences, 16(1), 3-10. DOI:10.1111/nhs.12068.

Spector, P. E., \& Fox, S. (2005). A stressor-emotion model of counterproductive work behavior. In S. Fox, \& P. E. Spector (Eds.). Counterproductive work behavior: Investigations of actors and targets (pp. 151-176). Washington, DC: American Psychological Association.

Spector, P. E., Bauer, J. A., \& Fox, S. (2010). Measurement artifacts in the assessment of counterproductive work behavior and organizational citizenship behavior: Do we know what we think we know? Journal of Applied Psychology, 95(4), 781-790. DOI: 10.1037/a0019477.

Sweeney, P. D., \& McFarlin, D. B. (1997). Process and outcome: Gender differences in the assessment of justice. Journal of Organizational Behavior, 83-98. Retrieved from http://researchcentral.ro/index.php?action=listateste\&ID=40 9.

Tyler, T. R., \& Blader, S. L. (2000). Cooperation in groups: Procedural justice, social identity, and behavioral engagement. Philadelphia: Psychology Press.

Uchenna, C. O. (2013). Counterproductive work behaviour among employees in emotionally demanding jobs: The roles of perceived organizational support, burnout, and age. Nigerian Journal of Applied Behavioural Sciences, 1, 105114. Research Methods, 39, 175-191. DOI: 10.3758/BF03193146.

Vredenburgh, L. D., Carlozzi, A. F., \& Stein, L. B. (1999), Burnout in counseling psychologists: Type of practice setting and pertinent demographics. Counselling Psychology Quarterly, 12, 293-302. DOI: 10.1080/09515079908254099 Yao, Y.-H., Fan, Y.-Y., Guo, Y.-X., \& Lee, Y. (2014). Leadership, work stress and employee behavior. Chinese Management Studies, 8(1), 109-126. DOI: 10.1108/CMS04-2014-0089.

Webster, L. \& Hackett, R. K. (1999). Burnout and leadership in community mental health systems. Administration and Policy in Mental Health, 2, 387-399. DOI:10.1023/a:1021382806009.

Wentzel, D. L., \& Brysiewicz, P. (2018). A survey of compassion satisfaction, burnout and compassion fatigue in nurses practicing in three oncology departments in Durban, South Africa. International Journal of Africa Nursing Sciences, 8, 82-86. DOI:10.1016/j.ijans.2018.03.004.. 